This item was submitted to Loughborough's Research Repository by the author.

Items in Figshare are protected by copyright, with all rights reserved, unless otherwise indicated.

\title{
An exploration of the co-production of performance running bodies and natures within "Running Taskscapes"
}

\section{PLEASE CITE THE PUBLISHED VERSION}

http://dx.doi.org/10.1177/0193723509340007

\section{PUBLISHER}

(c) SAGE Publications

\section{VERSION}

SMUR (Submitted Manuscript Under Review)

\section{PUBLISHER STATEMENT}

This work is made available according to the conditions of the Creative Commons Attribution-NonCommercialNoDerivatives 4.0 International (CC BY-NC-ND 4.0) licence. Full details of this licence are available at: https://creativecommons.org/licenses/by-nc-nd/4.0/

\section{LICENCE}

CC BY-NC-ND 4.0

\section{REPOSITORY RECORD}

Howe, P. David, and Carol Morris. 2019. "An Exploration of the Co-production of Performance Running Bodies and Natures Within "running Taskscapes"'. figshare. https://hdl.handle.net/2134/15947. 
An exploration of the co-production of performance running bodies and natures within 'running taskscapes'

\section{P. David Howe and Carol Morris}

Corresponding author:

P. David Howe

School of Sport and Exercise Sciences

University of Loughborough

Loughborough

LE11 3TU

p.d.howe@lboro.ac.uk

Carol Morris

School of Geography

University of Nottingham

University Park

Nottingham

NG7 2 RD

Carol.Morris@nottingham.ac.uk 


\title{
An exploration of the co-production of performance running bodies and natures within 'running taskscapes'
}

\begin{abstract}
This paper explores the interrelationship between particular 'natural' spaces and the production of middle and long-distance performance running bodies. It argues that running bodies and nature are actively co-produced, thus blurring the commonly made distinction between the 'social' and the 'natural'. In doing so, the paper extends the geography of sports literature by adopting a 'postconstructivist' perspective on nature as elucidated in Tim Ingold's (2000) concepts of 'dwelling' and 'taskscape'. This illuminates the (re)production of sporting bodies through the materiality of nature and in turn contributes to research on embodiment within sports studies that highlights the importance of space and the natural environment. The paper draws on ethnographic material and textual sources to illuminate the running taskscape associated with the production of performance running bodies and highlights how three forms and functions of nature are co-produced through this mode of dwelling.
\end{abstract}

\section{Introduction}

For those directly involved in the sporting practice of middle and long-distance running there has always been recognition of the significance of different material spaces, including in particular 'natural' spaces, in the production of 'performance running'1 bodies and, by implication, that running is an inherently geographical practice (Martin and Coe, 1991; Lydiard and Gilmour, 1962; Askwith, 2004). However, with a number of important exceptions (e.g. Bale 2003, 2004), critical scholars of both sport and nature-society relations have been much less attentive to this interrelationship. Indeed, social studies of sport have tended to neglect its geographies ${ }^{2}$ while social scientific studies of nature and natural environments, particularly those in human geography, have been little concerned with the body (Woodward, 1998; MacNaughton and Urry, 2000; Little and 
Leyshon, 2003). This paper responds to this neglect by exploring the production of performance middle and long-distance running bodies and the role of particular - 'natural' - spaces in this process. It does so in large part because middle and long-distance running, unlike many other sports (including other types of performance running such as sprinting), is a spatially extensive practice involving multiple sites, spaces and places and has a particularly close relationship with 'natural' spaces, both in terms of training and competition as evidenced in the disciplines of cross-country and fell running. Our objective, then, is to examine the interrelationship between performance running bodies and natural spaces as this is played out within western contexts ${ }^{3}$. However, we seek to problematise the uncritical acceptance of the idea of 'nature' and its sister concept 'environment' in our analysis and so a central part of our task is to take seriously recent scholarship that has sought to challenge commonly held assumptions about specific forms of material space, notably those that are understood as 'natural', and to work through the implications of this thinking when attempting to make sense of the production of performance sporting bodies.

The paper begins with a brief review of geographical scholarship that focuses on the relationship between society and nature highlighting the recent interest in 'post-constructivist' attempts to reconceptualise this relationship. It is followed by a discussion of the sociology of sport literature that focuses on the sporting body to illuminate the importance of habits, routines and practice in understanding the production of the running body. These two literatures are drawn together through Tim Ingold's (1997, 2000) post-constructivist notions of 'dwelling' and 'taskscape' that provide a means of approaching the spatial and temporal co-production of performance running bodies and nature. This is followed by a section describing the running taskscape of middle and long distance performance running through one 'fictional' running body (after Weber's ideal types in Runciman, 1978), a methodological device that is based on participant observation of two groups of runners by one of the authors, the first conducted over an eight year period in a city in Wales and the second conducted over a three year period in a town in England, and an interpretation of various running texts. The elucidation of the running taskscape reveals how the running body and nature are co-produced in this mode of dwelling albeit at timescales that are 
somewhat discordant with one another, making the transformations of the body more visible than those of its co-produced natural environments. The analysis identifies three forms and functions of nature - as a gymnasium (physiological function), a clinic (rehabilitative function) and as a shrine (spiritual / emotional / psychological function) - and comments on the character of natures' transformation. The paper concludes with a reflection on the contribution of post-constructivist perspectives on society and nature within sporting contexts.

\section{Understanding natural spaces: human geographical perspectives}

In their introduction to the collection of essays entitled Bodies of Nature, MacNaughton and Urry observe a neglect, within the sociology of the body literature, of "the various social practices that are involved in being in, or passing through, nature, the countryside, the outdoors, landscape or wilderness" (2000, p.1). To this observation we would add that there is a tendency within this same literature to take for granted the spaces or environments in which those bodies are made, conceptualising them as backdrops or material 'stages' on which those bodies are produced (Williams and Bendelow, 1998; Shilling, 2005). Recent geographical scholarship would regard these assumptions as problematic, particularly as they relate to spaces commonly regarded as 'natural'. An evolution in thinking about nature, and society's relationship to it, has occurred within the discipline ${ }^{4}$ and this needs to be understood if we are to fully comprehend the creation of the performance sporting body and the role of particular forms of material space within that process. As such, this section provides a short overview of the debates around the relationship between nature and society within the discipline of geography.

The dominant mode of thinking within contemporary human geography about the relationship between society and nature has been traditionally one of 'environmental realism', a position that draws a clear ontological distinction between society, on the one hand, and 'nature' on the other (see Castree, 2005 for an extended discussion of the treatment of nature in the whole of the discipline's history). Environmental realism is evidenced within the sub-disciplines of resource and environmental management (e.g. Wilson and Bryant, 1997). In this perspective 'nature' is 
understood as preceding or pre-existing the social. It is a domain that can be objectively known and measured, typically using scientific methods, including those of social science. Arguably, this represents a 'common sense' or lay understanding of nature, something that is 'out there', distinct and separate from 'us' and as such, something that can be 'impacted' on by 'us'. This, so the critics argue, tends to lead to a way of thinking about environmental problems (arising from societal impacts) as issues that need to be rectified through technical fixes and management strategies rather than through any fundamental questioning of the organisation of society itself; the underlying causes leading to the environmental problems. Instead, the focus is placed firmly on the symptoms, i.e. the environmental problems. As such, environmental realism has been criticised for its status quo thinking (Castree, 2001). Moreover, critics have suggested that an environmental realist framework tends to encourage an approach to the natural world which is focused purely on environmental problems, rather than recognising a variety of 'non-environmental natures' such as the human or animal body (Castree, 2001).

Challenging the existence and relevance of the boundary between society and nature is a range of approaches labelled ‘social nature’ or ‘socionature’ (Castree, 2001). Social nature includes social constructivist analyses of nature, although it is important to acknowledge that constructivist approaches are diverse, including ‘material constructivism’ (neo-Marxist); ‘discursive / linguistic constructivism' (inspired by the cultural turn); and material-semiotic constructivism (Demeritt, 1998, 2001, 2002; Castree and Braun, 2006). In spite of this internal diversity constructivist conceptions of nature would agree that the notion of an objective, pre-social nature is problematic, and argue instead that nature is always and everywhere thoroughly social "with serious implications” (Castree, 2001, p.5). Nature, in this way of thinking, can only be understood as socially mediated, such that there is never just 'one' nature, but many natures according to the social or cultural group relating to a particular environment. Constructivists argue that their perspective is politically significant since "viewing nature as a non-social domain [as in the environmental realist position] can lead to the perpetuation of power and inequality in the wider world” (Castree, 2001, p.5). Extreme (or 'hyper') constructivist positions (Demeritt, 1998) argue 
against the existence of any material nature that cannot be wholly remade by society, but most scholars adopting a constructivist perspective would dispute this, favouring instead a position that recognises a material nature but that this always has to be approached and understood through social processes. Although constructivism appears to break down the ontological boundary between society and nature, it actually ends up maintaining it through its overemphasis on the domain of human sociality. Another criticism of the approach is nature as a material entity tends to disappear within constructivist accounts as everything ends up being 'just' social. Nature, in these accounts, tends to be over socialised; a representation or a linguistic construction.

Partly as a reaction to the theoretical impasse produced by the divide between realist and constructivist positions, a further body of (rural) environmental geographical scholarship has emerged during the last decade that builds on the political radicalism of constructivism but takes more seriously the materiality of nature and the ‘nonhuman' more generally (e.g Whatmore, 2002). Influenced in particular by developments within the sociology of science society, it has been realised, is 'more than' human and cannot be reduced to social relations alone (Buller and Morris, 2007). The non-human (both living and inorganic) is, in this view, an integral part of 'the social' and vice-versa. Such an intellectual manoeuvre necessarily challenges the idea of a clear boundary between nature and society, indeed it questions the very meaning and existence of those categories (Latour, 1993). Although, like constructivism, post-constructivist ${ }^{5}$ thinking is internally diverse a common theme is the notion of 'relationality'. In other words, "the actions of 'social' and 'natural' phenomena upon one another is a relational achievement, not a case of discrete domains colliding with and controlling or subsuming the other” (Castree and Braun 2006, p.168). In this relational way of seeing so-called natural entities are brought into being through their relationship with socalled social entities, the one does not precede the other; instead, running bodies and nature are coproduced through daily and routinised practice.

The significance of practice within post-constructivist perspectives on nature provide a segue into the literature on the sociology of the body since sporting practices are, necessarily, 
embodied. In the following section we highlight those sociological approaches that offer conceptual insights into the embodiment of performance running.

\section{The habit of performance runners}

In order to fully understand performance running the concept of embodiment needs to be brought into the analysis. Kimayer has suggested that

Embodiment works against the tendency to treat bodies simply as property (my body and yours) or as vehicles entirely subordinate to our will. The essential insight of embodiment is that the body has a life of its own and that social worlds become inscribed on, or sedimented in, body physiology, habitus, and experience (2003, p. 285).

Over the last two decades the sociology of sport has placed increased importance upon the study of sporting embodiment. This work has been influenced by French social theory particularly the writings of Bourdieu and Foucault (Howe, 2004). From a methodological perspective embodiment postulates that the body is not an object to be studied in relation to the cultural world but is the subject of culture or the existential ground of culture (Csordas, 2002). In other words the performance sporting body is (re) produced within and by the social environment. In the context of performance running bodies can be disciplined through the creation of habit by the repetitive rudimentary drills that are set down by coaches to enhance the efficiency with which the body works when engaged in sporting practices. This concept has been, in one form or other, perhaps unconsciously, a focus for coaches' training procedures for generations. Alongside this, the role played by the use of 'natural' spaces in the training of high performance running bodies has long been acknowledged (Kelly, 1964). Therefore training regimes that work on the body can be related to the theory of practice developed by Bourdieu (1977, 1984, 1990a) including in particular the concept of habitus. As a result this position may be adopted to explore the performance running body and how this can be transformed by the material spaces in which training takes place (Howe, 2006). 
A runner's habitus is continually being transformed over time and is the embodied sediment of every encounter they have had with the social world (Bourdieu, 1977, 1984, 1990a, 1990b). As a result the physical action of runners is strategic and the better it is the more embodied cultural capital or physical capital a performer possesses. Qualities that are associated with performance running bodies such as speed, strength, and stamina are all part of what is required for a runner to archive physical capital within the culture of running where these physical attributes are revered. Bourdieu's concept of habitus is closely linked to Merleau-Ponty’s (1962) corporeal schema that articulates nicely the embodied agency of a runner both as an individual and as a member of the social environment surrounding training and competition (Howe, 2004). The corporeal schema comprises the skills required for the performance and the practical understanding of the competition that may be transformed depending on the action of other runners. Development of a running habitus entails the continual modification of corporeal schema through the process of sedimentation that runners undergo when they engage in variegated training regimes.

This conceptualisation of corporeal schema is of importance when trying to determine how runners (and other actors) make the decisions they do without really thinking about them. When an athlete makes a strategic move in a race they do not have to think about running or accelerating in a sense they 'know without knowing'. According to Crossley 'the corporeal schema is an incorporated bodily know-how and practical sense; a perspectival grasp upon the world from the 'point of view' of the body' (Crossley, 2001, p. 123). Corporeal schema, and the embodied knowledge that it entails, therefore need to be excavated in order to establish how the relationship between particular material spaces and the body help to formulate a performance athlete. This know-how gives the runner the raw material to turn into habit and hopefully over time enable them to become more proficient at racing.

Physical action that becomes embodied in certain situations may be seen as habitual and these acts are often drilled into an athlete through countless repetition that lacks imagination. Habitual acts that are further developed by improvisation can be considered dispositions (Ryles 1949). The disposition is the embodied ability to put the habitual training together in such a way 
that it can be quickly adapted to suit any situation. When an athlete goes through the training regime required of an elite middle distance runner his or her body habitually knows what the 'race-pace' is simply by the 'feel' of the body there is no need to rely upon a stopwatch. Changes that occur within a race in terms of the tactics of the other competitors and the ability of the athlete to respond are directly linked to the disposition or the ability to improvise that the athlete innately has developed through physical training and lived experiences more generally (Howe, 2006, p. 328). Disposition can be used in the present to mould perception, thought and action to the extent that it has an important role to play in decisions that an agent might make in future encounters. In this sense actors in general and, in the case of this research, performance middle distance runners that are manipulated by the coaches specifically, can be seen not simply to follow rules but also to bend them in much the same way as Merleau-Ponty (1965) conceptualises improvisation as being fundamental to an individual's disposition. Therefore the creation of habit through the discipline of training and racing undertaken by runners may lead to the development of a flexible disposition that is central to the performance running body. We now turn to exploring the spatialities of this process in the following section.

\section{Co-producing running bodies and nature: dwelling and taskscape}

Integrating the two corpuses of work outlined above is potentially a very tall order. Since our task is to try and make sense of the interrelationship between the performance running body and nature, we might ask whether our entry point should be the former or the latter and if it is either one, then might this run the conceptual risk of pushing the other into the background? How can we discuss, and make conceptual sense of, the running body and nature(s) simultaneously? One 'postconstructivist' and embodied concept, that seems to hold particular promise in this regard is the notion of 'dwelling' as initially conceptualised by the anthropologist Tim Ingold $(1997,2000)$ but subsequently adopted and adapted by rural and environmental geographers (e.g. Jones, 2006; Cloke and Jones, 2001; Wylie, 2003) and sociologists such as MacNaughton and Urry (2000) and Carolan (2008) who are interested in the interrelationship between bodies and nature. For Ingold the 
challenge is to overcome the divide between humanity and nature, by bridging the gap between natural science and the arts/humanities through a drawing together of insights from diverse intellectual currents.

Within this broad endeavour, Ingold devised the notion of dwelling, key to which is the reembedding of "human relations within the continuum of organic life” (Ingold 1997, p.249). Dwelling entails the immersion of the 'organism-person ${ }^{6}$ within, rather than on, an environment or life-world that, rather than being pre-given, comes into being around the inhabitant as they actively engage with it through their regular pattern of activities, including work, travel and domesticity ${ }^{7}$. The importance of work to dwelling is highlighted in Ingold's notion of 'taskscape' and is a feature of the conceptualisation that is particularly relevant to a consideration of performance running as this activity is better understood as work rather than leisure (Bale, 2004; Howe, 2004), entailing disciplined and routinised activity within the same environments (typically experienced in a rather functional sense as means of producing a performance running body). Ingold uses the term 'task' to help describe the practices of work and defines it as "any practical operation carried out by a skilled agent in an environment, as part of his or her normal business of life. In other words, tasks are the constitutive acts of dwelling” (Ingold, 2000, p.195). He goes on to define the 'taskscape' as follows:

[I]t is to the entire ensemble of tasks, in their mutual interlocking, that I refer by the concept of taskscape. Just as the landscape is an array of related features, so - by analogy - the taskscape is an array of related activities (Ingold, 2000, p.195).

Building on Ingold's concept of the taskscape, the notion of a 'running taskscape' is proposed as a means of making sense of the co-production of performance running bodies and nature. As this last quotation highlights, dwelling places particular emphasis on action and movement rather than simply cognition, a feature of this conceptualisation that is particularly pertinent to an understanding of sport since, as the previous section outlined, it necessarily implies a focus on embodiment ${ }^{8}$.

Indeed, Ingold states explicitly that he welcomes the 'embodiment paradigm' in the social sciences and humanities but suggests that it does not go far enough. For him, the study of 
embodiment needs to "recognise that the body is the human organism, and that the process of embodiment is one and the same as the development of that organism in its environment” (Ingold, 2000, p.170). He illustrates this in his remarks about movement through a landscape, up hills and down into valleys involving 'different muscular entailments', and that the contours of the landscape "are not so much measured as felt - they are directly incorporated into our bodily experience" (Ingold, 2000, p.203). A landscape therefore enters our 'muscular consciousness' and at the same time movement becomes 'embodied' "on the side of the landscape, in its network of paths and tracks. In this network is sedimented the activity of an entire community [runners and non-runners alike], over many generations. It is the taskscape made visible” (Ingold, 2000, p.204). From a dwelling perspective then, "the relationships with what is taken to be nature are embodied, involving a variety of senses” (Jones, 2006, p.189), particularly smell, sound, vision, and also kinaesthesis. The latter is "the sense that informs you of what your body is doing in space through the perception or sensation of movement in the joints, tendons and muscles” (Lewis, 2000, p.). A body in motion (e.g. a running body) is a body endowed with kinaesthesis. Dwelling, therefore, "is a complex performative achievement of heterogeneous actors [i.e. both human and non-human] in relational spatial / temporal settings which can only be grasped in the practice of their unfolding” (Jones, 2006, p.189).

Different dwellings, and their associated taskscapes, according to MacNaughton and Urry (2000), 'produce' ${ }^{9}$, different natures and this observation is particularly pertinent to our elucidation of the running taskscape. Drawing on Ingold they distinguish between 'land' and 'landscape' as contrasting modes of dwelling and, by implication, as co-producing different natures. The former is closely associated with work, where land is 'a physical tangible resource that is ploughed, sown, grazed and built upon' and, as a mode of dwelling, implies a functional relationship with nature. The latter is associated with a visual sense, and, when dwelt in as a 'leisure landscape' is typically temporally and spatially separate from the spaces and places of daily work and domestic routines. Although elements of both land and landscape as modes of dwelling can be evidenced within the taskscape of performance running neither adequately encapsulates this particular mode of dwelling 
and the natures that are co-produced through this social practice. As 'work' performance running can be primarily understood as a mode of dwelling involving 'land' that co-produces particular natures. However, although the visual is less significant within the taskscape of performance running than other senses, notably kinaesthesis, this activity can and does occur in spaces and places distinct from the everyday. Elements of both land and landscape as modes of dwelling are therefore relevant to understanding the taskscape of performance running and its distinctiveness as a taskscape. Further, rather than one form of nature emerging in the context of this mode of dwelling, a number of different natures are co-produced by this particular type of social practice as the subsequent section of the paper will go on to demonstrate.

Within the concept of dwelling, the specific notion of 'affordance' is particularly resonant with our task of understanding running bodies in relation to particular, natural, spaces. Affordance, according to Ingold, is Gibson's (1979) key insight in relation to ecological perception ${ }^{10}$. Perception, and the knowledge obtained through perception is practical with the person perceiving the environment through the movement of the whole being (mind and body together) within its environment. As Ingold elucidates,

depending on the kind of activity we're engaged in [e.g. running] we will be attuned to picking up particular kinds of information [e.g. about the body, its surroundings and the relationship between them]. The knowledge obtained through direct perception is thus practical, it is knowledge about what an environment offers for the pursuance of the action in which the perceiver is currently engaged. In other words, to perceive an object or event is to perceive what it affords (2000, p.166)

The world that surrounds us takes on its meaning and purpose by what it affords and how it is incorporated into daily activities. Although Ingold finds Gibson's concept of affordance highly insightful, he suggests that Gibson assumes the world is relatively fixed and prepared "with all its affordances ready and waiting to be taken up” (Ingold, 2000, p.168) by its inhabitants. In contrast, Merleau-Ponty’s phenomenological perspective sees the world as emerging alongside the person in the context of 'involved activity', emphasising the idea of the co-production of both running bodies and natures. As MacNaughton and Urry (2000, p.169) observe, “affordances are both objective and subjective, both part of the environment and part of the organism. They stem from the reciprocity 
between the environment and the organism, deriving from how people are kinaesthetically active within their world. Affordances constrain behaviour along certain possibilities, connected to bodily capacities and limits of the human organism (albeit augmented by various objects and technologies: boots, coats, compass, food and so on)”. When exploring the production of performance running bodies a number of affordances unique to the environment of the running taskscape can be identified as we reveal in the next section that describes the taskscape associated with middle and long-distance running.

\section{Methodological note}

In order to work through the ideas on dwelling as a means of understanding the relationship between 'natural' spaces and high performance running bodies in this section the taskscape of middle and long-distance running is described, as this unfolds over a period of training that is organised into six phases over the course of one calendar year ${ }^{11}$. Within this period the work that the running body performs in the variety of environments that comprise the taskscape enables its transformation. At the same time, the multiple natures of the taskscape are also revealed. Specifically, three forms of nature are co-produced through this mode of dwelling, each with a distinctive function with respect to the production of the high performance running body. Nature is not simply 'there' to be uncovered or discovered by the runner but actively emerges in a variety of forms through the habits, routines and practices associated with the work of producing the high performance running body. Bodies and natures are produced simultaneously, or, are 'co-produced'. Furthermore, and in line with MacNaughton and Urry's (2000) assertion that different modes of dwelling produce different natures, when and where the taskscape of running incorporates 'land' (cf 'landscape') as a mode of dwelling, it entails a relatively functional relationship with nature.

The body of one runner, Richard, is used as a methodological device for elaborating the running taskscape. This approach is an interpretation of Weber's 'ideal type' (Runciman, 1978) that is, according to Hammersley and Atkinson (2007, pp.195-6), an “analytic construct. It does not, and is not intended to, correspond in every detail to all observed cases. It is intended to capture key 
features of a social phenomenon”. In a sport specific context, the ideal type has been utilised effectively by Klein (1993) in his construction of the 'Olympic Gym', a single fictitious gym that is used as a vehicle for representing four similar gyms in which he conducted ethnographic research. Likewise, Richard is a fictional creation in that he represents an amalgamation or distillation of ethnographic research into middle and long-distance running. This research entailed participant observation of two groups of runners, both conducted by one of the authors. The first group was observed over an eight-year period in a city in Wales (Howe, 2004) and the second over a threeyear period in a town in England. Because of the similarities in the practice of training associated with high performance running across numerous individuals and through time, it is a logical development in the reporting of ethnographic data, to create one fictional runner that embodies the sameness of experience. The account of the running taskscape is also based on a close reading and interpretation of a variety of texts including coaching manuals (Martin and Coe, 1991; Lydiard and Gilmour, 1962; Daniels, 2005; Stampfl, 1955), biographies of famous runners and coaches (Buckner, 1989; Gilmour, 1963; Turnbull, 1982; Snell and Gilmour, 1965), and other non-fictional accounts of running (e.g. Askwith, 2004; Lear, 2003; Bale, 2004; Howe, 2006).

\section{The running taskscape}

Richard is 22 years old and lives in the small market town of Runtleborough in central England. The town has a population of approximately 65,000 , covers an area of 4 square miles ${ }^{12}$ and is bisected by a canal with an adjoining towpath. Within the town's boundaries are a number of small public parks (characterised by ornamental planting, grass and paths) and a former railway line that has long since been converted to a public footpath. It is situated on the banks of the river Sloane, and is surrounded by gently rolling countryside comprising mostly agricultural land of hedged fields (both ploughed and under grass), bordered and crossed with footpaths and scattered with small wooded areas, some of which are accessible to the public via footpaths and bridleways. Approximately four miles from the town centre is a 'Country Park', a hilltop site containing areas of semi-natural and recently planted woodland and open grass fields and represents an important 
recreational environment for local people, including runners. Richard belongs to the local athletics club, 'Runtleborough AC', which has a well-established reputation for producing international track and field athletes in a number of different disciplines, including Richard's discipline of middle / long distance running. Training of middle and long distance running within the club is organised around a group of 20 athletes with a dedicated coach, a group that represents a sub-culture of high performance running within the overall habitus of the club

Richard has been running since he was 14 years old and was inspired to participate in the sport by watching on TV the achievements of runners such as the Ethiopian Haile Gabrselassie and the Algerian Noureddine Morcelli, and parents who, as welfare runners (Bale, 2003) that had both participated in big city marathons, encouraged him to join the athletics club when he showed an interest in sport. Having now spent 8 years in the sport Richard has become a good, national level runner, reflected in his recent success gaining sponsorship from a footwear manufacturer. This financial support enables him to devote most of his time to the development of his running while working part-time at a local running shop which facilitates the flexibility required for his training and racing. Running, for Richard, is his 'employment', and a significant portion of each day is spent in training, resting and eating. He is aspiring to eventually represent his country in major international competition. In order to work towards this, his body requires rigorous training to produce four key characteristics that high performance runners need to embody: endurance, strength, speed endurance and speed. Each of these characteristics, elaborated in the phases of training below, requires a particular set of habits and routines that collectively constitute a central part of the running taskscape. The temporalities and spatialities of this training are also integral to the taskscape (indeed, one cannot be separated from the other), a taskscape that produces running bodies as it simultaneously produces a number of different natures.

We first encounter Richard at the beginning of his autumn training phase. During these months his body will travel between 80-90 miles a week in the course of training, a distance that will reduce to 40-60 miles in the competitive track season during the subsequent summer months. In autumn and winter, his training is focused on cross-country competitions as a means of 
strengthening his body with the aim of enhancing its performance in the more rationalised space of the running track. The first phase of training allows Richard's body to build up its capacity to run large amounts of miles in a week, starting with approximately 40 miles per week and increasing this by ten percent each week until Richard is running over 70 miles per week. The overall aim is to enhance the body's endurance capabilities as the mileage is increased each week. As this increase occurs the coaching advice is for him to undertake $70 \%$ of his running 'off road', in the semiunrationalised spaces such as playing fields, canal towpaths, rural footpaths and parkland in and around Runtleborough. Such spaces, with their typically 'softer' and gently undulating surfaces of grass, mud and wood chips afford impromptu massage of the calf muscles that can become over tight if too much running takes place on hard tarmac surfaces. Every other day Richard will run a route that incorporates some hills, in and around the Country Park, where he will add effort on the uphill portion of the run, an exercise that helps build strength in his legs and illustrates how, in Ingold's terms, the landscape enters the runner's 'muscular consciousness'.

There are two key training sessions a week in the second phase of the period which coincides with the cross-country season, and runs from November to the end of March. Initially these key training sessions are 'unstructured'. The first session is a tempo run over approximately 6 miles, run continuously at a steady pace that Richard can sustain for the distance on hard surfaces i.e. roads and pavements around the town. The run takes place on a Tuesday evening, as part of the athletic club’s training night. In each week of the initial month of training, the runners increase slightly the intensity of effort. The second session, in the early stages of this period, is a 'fartlek' or speed play, run over rolling terrain off-road. This session is designed to allow athletes to run 'as they feel' while also increasing their strength and endurance capabilities through the presence of the inclines. The off-road location of this run means that it is typically undertaken on a Saturday morning, when the light is good i.e. the temporality of this component affords certain conditions that allow Richard to run in areas that are not illuminated with artificial light. In and around Ruttleborough, this element of training often takes place in a woodland site, 'Coronation Woods', a semi-natural woodland on a small ridge to the south-west of the town. The woods themselves afford 
a rolling dirt track (which winds its way through the trees) around their perimeter (approximately three kilometres) that is soft under foot, being occasionally covered with bark chips in places and wooden planks in others where the path is susceptible to being water-logged, and contrasts with the hard surfaces of the town's roads.

These two initial periods of training begin to reveal what is arguably the dominant form of nature in the running taskscape: 'nature as a gymnasium', the function of which is physiological. As in an indoor gymnasium within which different sites (sometimes associated with pieces of equipment) enable the body to be worked on in different ways (Andrews et al. 2005), so nature as a gymnasium, through its variety of gradients, uneven, unstable and softer surfaces, affords a particular set of opportunities for strengthening, increasing stamina and developing speed endurance in the running body. This is also evidenced in the related but distinct taskscape of fell-running where the development of 'fell hardness' is a distinct feature of the running body produced through training in the environment of the fells themselves. "Fitness alone isn't enough to get you through this kind of thing. Mastery of the mountains - fell hardness...- is the key” (Askwith, 2004, p.44). Askwith highlights how the gymnasium of the fells (our interpretation) affords a highly distinctive running environment: "even the fastest fell-racers lack pace on the road in comparison with flatracers, even marathon-runners...you use a completely different lot of muscles on the flat" (2004:125).

Some of the routes Richard follows on his numerous weekly runs (up to a dozen per week) will have been passed down to him by more senior members of his club. Other routes he will have established himself through trial and error and local maps that are used to plan training runs. In addition to the numerous pavements within the town itself, these runs can incorporate the Country Park and Coronation Woods as well as smaller town parks, playing fields, footpaths on field edges and canal towpaths. His favourite routes may eventually be passed on to other members of his club as the process repeats itself. His ‘wayfinding' (Ingold, 2000) ${ }^{13}$ during his training runs therefore entails repeated use of particular routes that combine the necessary mixture of different surfaces and 
visual stimuli that help to maintain an enthusiasm for training. Over time some routes may become very well known through use and reuse by runners and may be given particular names.

Phase three in Richard's training lasts for approximately 8 weeks and involves structured repetitions ${ }^{14}$ on well-groomed and relatively flat playing fields on a Tuesday evening. This location affords better visibility for the runners at a time in the year when the days are short and is easier to police by the coaches. The grass surfaces of the playing fields afford Richard's legs a break from the unevenness and undulation of less managed terrain. These sessions are used to improve Richard's speed endurance. The Saturday morning session in this phase comprises structured hill repetitions ${ }^{15}$ with each repetition emphasising relaxed efficient running where the descent is as important as the ascent. On the ascent, the aim is for the hill to 'do the work'; staying loose in the shoulders, relaxed and at full stride (if Richard 'works' up the hill his stride will be 'chopped'). When the club has a cross-country competition on a Saturday these races are scheduled as replacements for the hill session and are run as if they were a tempo run within a competition where the focus is upon building the body's ability to provide itself with oxygen while under stressful conditions. The cross-country races typically take place on various forms of publicly owned parkland (and not, therefore, 'country' in a conventional sense) where the courses are undulating and have uneven surfaces which can get boggy during the winter months. This uncertain footing helps to strengthen Richard's body. The courses are temporarily established for the races through the use of removable barriers. Some of these courses will be within the same space, year on year (although this will have changed often in an unnoticeable way), allowing runners to become familiar with their contours, routes, muddy patches etc.

The fortnight at the end of the calendar year is a period of consolidation in Richard's training schedule. The intensity of training does not increase but is maintained to allow Richard's body to recover and regenerate in preparation for the next serious phase. The second week of the new year marks the beginning of the fourth phase in training: a twelve week cycle that is distinctive from the previous three cycles in that it has a series of four micro-cycles, each of which entails three weeks of activity where the training becomes progressively more intense, followed by one week 
where the work-load is less intense. Each micro-cycle is established to allow Richard to recuperate from the more intense training that is involved in this twelve week period. Because Richard's weekly mileage is now consistently at its maximum, each week incorporates three key sessions, each of which is designed to have different 'training effects' and each takes place in different spaces within the taskscape. A session of interval training either takes place on a tarmac hill in Runtleborough town or on the running track and is designed to tax the body and to increase the body's ability to supply itself with oxygen at intense levels of activity (stress the body's aerobic capacity). The adaptation of the body occurs during the breaks in training effort (Daniels, 2005). A tempo run, the week’s second session, occurs either on parkland or on the pavements around the town depending on the time of year as during the late winter and early spring there may not be enough light to make use of off-road running environments in the early morning and evening. The third session in this phase is specific cross-country preparation conducted on some of Runtleborough's playing fields and the grassy slopes around their perimeter, an environment within the taskscape that has been regularly used for local cross-country races. Importantly, the perimeter slopes are not as well groomed as the fields used for the Tuesday sessions prior to the end of the previous calendar year and as such afford a different kind of running. They represent distinct sites within nature's gymnasium. Richard and the other athletes are forced to exaggerate their cadence by lifting their feet with the effect of positively stressing the calf muscles, an activity that will benefit him when he returns to the more rationalised space of the track in late spring. The fourth week of the micro-cycle is to provide Richard with a small opportunity for bodily regeneration (but not a complete rest) incorporating two sessions. The first of these is a 30 minute Fartlek run within the urban environment of the town and the second is a 2000m time trial over the fields used on the Saturday sessions. This allows Richard and his coach to obtain an understanding of his relative fitness as he progresses through this twelve week period of training. The time trial takes place on playing fields rather than on tarmac because it is oriented to the typical environment of crosscountry competition i.e. it is the same environment as the competitive spaces during this training period. 
In the spring time, around April / May, athletes from Richard's club normally train away from home to begin the next phase of training. A popular destination for middle and long distance runners will be spaces that have provided favoured training places for great champions of the past (i.e. these training camps are not held 'just anywhere'). These might include the sand dunescapes such as Merthyr Mawr in South Wales and high altitude locations such as Albuquerque, New Mexico. Each environment affords distinct opportunities and challenges for the middle and long distance running body. Running in the sandy conditions of dunes strengthens the legs and lungs because the surface is very unstable and gives way a little at every step, so the runner has to work harder in order to move forward. High altitude environments afford reduced oxygen and after acclimatisation an athlete who trains in these conditions are believed to develop improved cardiovascular efficiency shortly after their return to sea level or much lower altitudes. Aside from the physiological advantages that are believed to accrue from training in these environments, training camps of this kind enable athletes to focus exclusively on training as they are removed from their daily routines. They are by no means a holiday or respite from training. Furthermore, by giving the athlete a 'break' from the environments in which they train on a regular basis it is believed that it freshens and invigorates the running spirit, partly through the association of these places with the success of past middle and long distance running champions. This year Richard and his training group travel to Merthyr Mawr, most famously associated with the middle distance running legend Steve Ovett (Turnbull, 1982; Wilson and Patmore, 1982).

It is here that a second form of nature emerges, and one that is associated more with 'landscape' than with 'land' as a mode of dwelling i.e. it has a strong, but not exclusively, visual component and is often - although not exclusively - experienced in places and spaces distinct from those of daily running routines. Nature here is a shrine, the function of which is predominantly spiritual, emotional and psychological when it provides respite - through its peace, beauty and opportunities for solitude - from other aspects of the running taskscape (e.g. roads and other features of the built environment) as well as inspiration through association with past champions. In the case of Merthyr Mawr particular natural spaces beyond those encountered in the daily routines 
of the running taskscape become places of pilgrimage and the act of training the body in those spaces serves to stimulate and encourage the runner to greater achievements.

In the process of ascending the largest dune at Merthyr Mawr known as the 'big dipper'(as it is approximately $100 \mathrm{~m}$ high) Richard suffered a minor tear in his calf muscle which subsequently side-lined him from serious training for several weeks. For the first week after the injury occurred Richard was advised to not run at all and therefore his training environment became the local swimming pool. In the pool he wore a flotation device and underwent a series of 'aqua-jogging' training sessions. After the first week Richard was able to test his injury with a light 10 minute jog on the soft, even grass of playing fields which afford a rehabilitative environment in this context. After gentle stretching and icing and an evening's rest, Richard confirmed that everything had healed and so was encouraged back into the pool for a couple of days, followed by the 10 minute run in the same environment; a cycle that was repeated several times until he experienced no illeffects from the run. Once Richard is able to run pain-free he will increase his weekly mileage to half of his winter work-load before progressing into an intense training session. This period of injury sees nature performing a rehabilitative function in the running taskscape. When the running body is injured, the spaces of playing fields, the 'un-made' trails in woodlands and country parks, together with canal-side and other off-road footpaths afford a range of softer and more forgiving surfaces that protect and support, and also 'massage' through their roughness and instability, damaged muscles, tendons and ligaments. A further illustration of this is provided by Askwith (2004) who, in his reportage of the taskscape of fell-running, describes a conversation with a fellow fell-runner about his Achilles tendon injury. While the runner complained of some pain "he felt that 'all this scree running is doing it the power of good'”(2004, p.32-3) as the loose surface of scree slopes gives way very slightly at every downward step. At these times these natural spaces become a 'clinic'. Within the running taskscape, however, other types of spaces in the built environment can also provide a rehabilitative function such as swimming pools i.e. nature is not the only form of rehabilitative space within the running taskscape. 
Having overcome this minor set-back, training on the fifth phase of the cycle (of 8-10 weeks) begins. The mileage that was maintained through the winter is reduced by about $15 \%$ as the intensity of the three important weekly training sessions is increased. Two of the three sessions in this period are conducted in the more rationalised space of the athletics track since the focus has shifted towards the competitive track season. The third of the key sessions at this time of year uses two distinctive spaces. The first entails Richard running a series of hill repetitions on three hard surfaces that converge at a single point that is a short jog from the Runtleborough AC track. The steepest of the hills is relatively short and therefore run at the fastest pace so as the hills get longer and more shallow the intensity of train the hills afford is decreased ${ }^{16}$. The second utilises the closely trimmed grass surfaces of a playing field to provide respite from the rationalised track space but also the use of spiked training shoes that can cause over-use injuries in the lower leg. The runs in between each training session are less intense than previously and undertaken mainly on grassy undulating surfaces surrounding agricultural fields, parkland environments and some woodland trails within and immediately surrounding Runtleborough. Nature as gymnasium is again significant at this point in the training cycle. Often the Saturday session is replaced by an early season race that is described as a 'conditioning event' i.e. preparing the body for the rigours of competition.

The summer period represents the zenith of Richard's running period (year). Like the other phases preceding it, it entails particular combinations of environments as highlighted above. Richard's mileage decreases again overall and at times during this period there is only one weekly training session because of the co-presence of a race in the same week ${ }^{17}$. It is accepted that the embodied habitus established during the winter and spring training carries Richard through this phase and the need to rest between intense efforts associated with competition is paramount. There may be weeks where no sessions are completed particularly in the lead up to national championships where two or three races may occur on subsequent days. Travel to races that are at a distance means that some of the running that is done simply to keep the body at peak fitness. There will also be a desire at this time to avoid uneven surfaces that would be sought out and celebrated at other times in the training cycle in order to avoid unanticipated twists to the ankle and Achilles 
tendon. Rationalised spaces take on a greater significance at this time on two levels. First, in terms of the competitive environment that is the athletics track and second, in terms of the training environment that is ideally closely cropped and regularly managed playing fields that are likely to be more 'forgiving' underfoot than tarmac.

The training that Richard has undergone above forms a single periodized (Coe, 1996) season during which his body has developed through the discipline and habit of training in the various environments of the taskscape, including but obviously not limited to the three forms of natural space which afford distinct opportunities for the making of the running body. Regardless of the success or failure of the season Richard will take as much as four weeks of active recovery away from running not only to give his body a rest but also to re-evaluate the successes and failures of the whole season with his coach. This period of reflection is required to determine what training habits need to become more embodied, be they focused on strength, endurance or speed, within the next phase of training. As a result of this contemplation the taskscape may be altered very subtly within the subsequent training period as the emphasis on developing particular bodily characteristics may lead to certain sites, and their associated affordances, being sought out and utilised more than others.

\section{Discussion}

This paper has explored the interrelationship between the high performance running body and 'nature', conceptualising this through Ingold’s $(1997,2000)$ post-constructivist notions of dwelling and taskscape. Specifically, the taskscape associated with middle and long-distance running has been described, as it materialises through a year-long period of training. A chronological account highlights the stages that the running body goes through in the journey towards its competitive performances. The account of the taskscape has also emphasised the multiple natures that emerge as the high performance running body moves through it. In this final section we consider some of the conceptual challenges that have emerged through this process, focusing on two in particular: the 
nature of the natures identified and the limits of the notion of 'dwelling' when a social practice based on movement is at the core of the analysis.

The multiple natures of the taskscape are revealed as both ideas / discursive constructions (i.e. they take on particular meanings for the runners and their bodies) and as material entities, providing a variety of affordances for the running bodies they co-produce. Further, any one site within the running taskscape can incorporate more than one of these forms of nature as, for example, when nature simultaneously emerges as a gymnasium and as a shrine. This is illustrated when the Runtleborough runners take a training 'pilgrimage' to Merthyr Mawr, but also as particular training routes developed by past champions within Runtleborough's environment are passed on to later generations of running hopefuls. Furthermore, any one site or series of sites within the running taskscape could be differently co-produced at different times so that a natural space that is initially experienced as a gymnasium, can on subsequent visits be co-produced - as a clinic or a shrine - depending on the particular phase of training. This serves to emphasise how natural spaces are by no means fixed and pre-given but are highly relational. However, this is a rather one-sided view of the relationship as it emphasises the meaning / function of the natures concerned to the high performance runner. The notion of co-production must entail a consideration of how natures' materialities are reshaped and transformed through their interrelationships with high performance running.

Discordant temporalities in the rates of change in bodies and natures present some analytical challenges here. The transformation of the high performance running body is clearly observable within a relatively limited period of time as the description of the running taskscape elucidates. However, its natures are more resistant to material change and more difficult to observe through social scientific investigation. Ingold, in discussing the temporality of landscape, draws attention to how it can appear passive and unchanging but is actually in motion albeit "on a scale immeasurably slower and more majestic than that on which our own activities are conducted" (2000: 201). Likewise, some of the changes occurring within the running taskscape are largely imperceptible in comparison with the time-scales where transformation occurs in the high performance running body 
and yet if natures' materialities are important to the analysis we must take these changes seriously. Nevertheless, as Ingold (2000: 203) observes, “people shape the landscape even as they dwell. And human activities, as well as the action of rivers and the sea, contribute significantly to the process of erosion”. Within the running taskscape, the effects of dwelling become evident through the actions of those who intervene in and manage particular environments that comprise the taskscape. For example, encroaching vegetation along path-sides within the taskscape e.g. on footpaths bordering agricultural land and along the canal and river, are trimmed several times during the growing season to enable their continued use. If this did not occur these paths would become impassable over the course of several seasons. Over a longer time period, the paths through Coronation Woods are resurfaced (with gravels, wood chips and wooden planks) when localised erosion arising from the repetitive footfalls of numerous runners becomes observable. The creation of a network of paths and tracks is, as Ingold (2000: 204) reminds us, “the taskscape made visible”. The eclipsing of this network, as vegetation grows over the paths and tracks through lack of use or management, or its erosion make visible changes within the taskscape.

There remains, however, a further analytical challenge as the running taskscape is not an exclusive space. It is not the runners alone that are creating these changes since the environments comprising the running taskscape are also shared with many others including hikers, mountain bikers and dog-walkers etc. It is difficult to disentangle the effects of running on the material changes to the natures of the taskscape from the effects of the other activities that share some of its spaces. That said, in places such as Runtleborough, that are well known for their association with high performance running, the natures of the running taskscape may well be reshaped to a greater extent by the activity of running than in those places where high performance running is less important. In addition, because the vast majority of the work involved in producing the high performance running body is undertaken within nature as gymnasium it is likely that these spaces will experience the greatest rates of change within the running taskscape.

These conceptual conundrums surrounding the natures of taskscape signal the need to consider the limitations of Ingold's notion of dwelling more widely. As outlined earlier Ingold's 
ideas have been applied in a number of contexts and clearly offer considerable analytical potential. However, in the course of this paper we have already made some suggestions for development, notably in the elaboration of the concept of the running taskscape, and the proposal that this taskscape as a distinctive mode of dwelling incorporates ideas of both land and landscape. That Ingold is almost entirely dependent on examples drawn from 'simple' societies to build his conceptualisation raises questions about its application within an entirely contemporary western context and one in particular - high performance running - that he was not concerned with at all. To do so is to test the analytic mettle of the concept of dwelling. We have suggested that dwelling does have meaning and conceptual relevance within the contemporary world and its social practices, including the practices surrounding high performance running.

An additional consideration is that the very word 'dwelling' suggests a rootedness in particular places. It might be argued that the activity of running (or indeed any movement based activity) is the very antithesis of rootedness. These concerns can be addressed in a number of ways. First, by placing particular emphasis on running as work and 'task' within the broader conceptualisation of dwelling enables running to be understood as an activity with distinctive temporalities and spatialities that constitute particular taskscapes. Second, according to Wylie, who voices similar concerns, albeit not in relation to the specific activity of running,

dwelling as a form of phenomenological ontology should...be the milieu for material cultures and ways of being that are productive of multiple spatialities and temporalities, long standing and momentary, rural and urban, fixed and mobile, coherent and fragmentary. In particular, it must enable the register of the transient and fleeting as well as the enduring (Wylie, 2003, p.145 emphasis added).

Wylie (op cit) goes on to argue that any definition of dwelling needs to operate as an "ontological milieu of involvement, rather than as a means of delineating what forms of practice count as dwelling”. Furthermore, and specifically in relation to high performance running:

practices of dwelling may be brief, may occur in different, momentary ways within different spatial and temporal contexts, and that practices of gazing are practices of dwelling. As opposed to a dwelling predicated upon 'rich, intimate, ongoing' 
experiences (Cloke and Jones, 2001, p.651) we might thus offer one lived through the occasional and the transient (Wylie, 2003, p.147).

Wylie suggests that dwelling involves multiple temporalities and spatialities. This recommendation is very apposite since running necessarily entails rapid and transitory 'passings through' various environments (that collectively constitute a mode of dwelling) rather than an anchoring of an activity within a particular space. Nevertheless, unlike Wylie’s concern to make relevant dwelling to single environmental experiences (in his case a walk up Glastonbury Tor) the discipline of running, specifically as this relates to the training of a high performance running body, typically entails a repeated following of the same routes through a particular place as the elaboration of the running taskscape has demonstrated. This suggests that the concept of dwelling and taskscape in particular has analytical relevance beyond the specific context of high performance running and could readily be extended to consider other forms of running within Bale's (2003) body-cultural trialectic and, indeed, other sports since the training for these are based upon habit and drill that are the product of repeated use of the same environments within particular taskscapes. Investigation of these other sporting contexts through the concepts of dwelling and taskscape would be worthwhile.

\section{References}

Askwith, R. (2004). Feet in the Clouds: a tale of fell-running and obsession. London: Aurum Press. Bale, J. (2003). Sports Geography. London: Routledge. Second Edition.

Bale, J. (2004). Running Cultures. London: Routledge.

Bale, J. and Sang, J. (1996) Kenyan Running: Movement Culture, Geography and Global Change. London: Frank Cass.

Bourdieu, P. (1977). Outline of a Theory of Practice, Cambridge: Cambridge University Press.

Bourdieu, P. (1984). Distinction: A Social Critique of the Judgement of Taste. London: Routledge.

Bourdieu, P. (1990a). The Logic of Practice. Cambridge: Polity Press.

Bourdieu, P. (1990b). In Other Words: Essays Towards a Reflective Sociology. Cambridge: Polity Press.

Buckner, J. (1989). Running the Distance: an athlete’s year. London: Heinemann Kingwood. 
Buller, H. and Morris, C. (2007). Animals and Society in Pretty, J., Ball, A., Benton, T., Guivant, J., Lee, D., Orr, D., Pfeffer, M. and Ward, H. (eds.) The Sage Handbook of Environment and Society. London: Sage, pp.471-484

Carolan, M.S. (2008) More-than-representational knowledge/s of the countryside: how we think as bodies. Sociologia Ruralis,

Castree, N. (2001). Socializing nature: theory, practice and politics in Castree, N. and Braun, B. (eds.) Social Nature: Theory, Practice and Politics. Oxford: Blackwell, pp.1-21.

Castree, N. (2005). Nature. London: Routledge.

Castree, N. and Braun, B. (2006). Constructing rural natures, in Cloke, P., Marsden, T. and Mooney, P. (eds.) Handbook of Rural Studies. London: Sage, pp.161-170.

Cloke, P. and Jones, O. (2001) Dwelling, place and landscape: an orchard in Somerset. Environment and Planning A, 33, pp.649-666.

Coe, P. (1996). Winning Running: successful 800m and 1500m racing and training. Marlborough. Wiltshire: Crowood Press.

Crossley, N. (2001). The Social Body: Habit, Identity and Desire. London: Sage

Csordas, T (2002). Body/meaning/healing. New York: Palgrave Macmillian

Daniels, J. (2005). Daniels' Running Formula: proven programs 800m to marathon. Leeds: Human Kinetics (Second Edition).

Demeritt, D. (1998). Science, social constructivism and nature, in B. Braun and N. Castree (eds) Remaking Reality. London: Routledge, pp.173-93.

Demeritt, D. (2001). Being constructive about nature in Castree, N. and Braun, B. (eds.) Social Nature: Theory, Practice and Politics. Oxford: Blackwell, pp.22-40.

Demeritt, D. (2002). What is the social construction of nature? Progress in Human Geography 2 (3), pp.255-79.

Gibson, J. (1979) The Ecological Approach to Visual Perception. London: Houghton Mifflin.

Gilmour, G. (1962). A Clean Pair of Heals: the Murray Halberg Story. Auckland:Reed.

Hammersley, M. and Atkinson, P. (2007) Ethnography: Principles in Practice. London: Routledge. 3rd Edition.

Hannigan, J. (2006). Environmental Sociology. London: Routledge. Second Edition.

Henderson, J. (1969). Long Slow Distance: the humane way to train. Los Altos. CA: Tafnews Press.

Howe, P. D. (2004). Sport, Professionalism and Pain: Ethnographies of Injury and Risk. London: Routledge.

Howe, P. D. (2006). Habitus, Barriers and the [Ab]use of the Science of Interval training in the 
1950s, in Sport in History. Vol. 26 (2). 325-344.

Ingold, T. (1997). Life beyond the edge of nature? Or the mirage of society, in J. Greenwood (ed.) The Mark of the Social. London: Rowman and Littlefield, pp.231-252.

Ingold, T. (2000). The Perception of the Environment: Essays on Livelihood, Dwelling and Skill. London: Routledge.

Jones, O. (2006). Non-human rural studies, in Cloke, P., Marsden, T. and Mooney, P. (eds.) Handbook of Rural Studies. London: Sage, pp.185-200.

Kelly, G. (1964) Mr. Controversial: the Story of Percy Wells Cerutty. London:Stanley Paul.

Kimayer, L. J. (2003). 'Reflections on Embodiment', in J. M. Wilce, J. M. (ed.) Social Cultural Lives of Immune Systems. London: Routledge. pp. 282-302.

Klein, A. (1993). Little Big Men: Bodybuilding Subculture and Gender Construction. New York: SUNY.

Latour, B. (1993). We Have Never Been Modern. Hemel Hempstead: Harvester/Wheatsheaf.

Lear, C. (2003). Running with the Buffaloes. Guildford, Connecticut: Lyons Press.

Leder, D. (1990). The Absent Body. London: University of Chicago Press.

Lewis, N. (2000). The climbing body, nature and the experience of modernity. Body and Society, 6 (3-4), pp.58-80.

Little, J. and Leyshon, M. (2003). Embodied rural geographies: developing research agendas. Progress in Human Geography, 27 (3), pp.257-272.

Lydiard, A. and Gilmour, G. (1962). Run to the Top. Auckland: Reed.

MacNaughton, P. and Urry, J. (2001). Bodies of nature: introduction, in P. MacNaughton and Urry, J. (eds.) Bodies of Nature. London: Sage, pp.1-11.

Martin, D. M. and Coe, P. (1991). Training Distance Runners: the art and science of optimal training. Leeds: Human Kinetics

Merleau-Ponty, M. (1962). Phenomenology of Perception, London: Routledge and Kegan Paul.

Merleau-Ponty, M. (1965). The Structure of Behaviour, London: Methuen.

Runciman, W.G. (1978) (eds.). Weber: Selections in Translation, Cambridge: Cambridge University Press.

Ryle, G. (1949). The Concept of Mind. London: University of Chicago Press.

Shilling, C. (2005). The Body in Culutre, Technology and Society. London: Sage.

Snell, P. and Gilmour, G. (1965). No Bugles No Drums. Auckland: Minerva.

Stampfl, F. (1955). On Running. London: Herbert Jenkins 
Turnbull, S. (1982). Steve Ovett: portrait of an athlete. London: Star Books.

\author{
Whatmore, S. (2002). Hybrid Geographies: Natures Cultures Spaces. London: Sage. \\ Williams, S. J. and Bendelow, G. (1998).The Lived Body: Sociological Themes, Embodied Issues. \\ London: Routledge
}

Wilson, G. and Bryant, R. (1997). Environmental Management. London: UCL Press.

Wilson, H and Patmore, A. (1982). Running Dialogue: a coach's story. London: Stanley Paul.

Woodward, R. (1998). 'It's a man's life!': soldiers, masculinity and the countryside. Gender, Place and Culture 5, pp.277-300.

Wylie, J. (2003). Landscape, performance and dwelling: a Glastonbury case study, in P. Cloke (ed.) Country Visions. Harlow: Pearson, pp. 136-157.

\begin{abstract}
${ }^{1}$ Drawing on Henning Eichberg's (1998) notion of 'body culture' that describes different configurations of particular bodily activities, Bale (2003) distinguishes three forms of running: free running associated with play; welfare running associated with health and fitness; and performance running associated with elite athletics. It is performance running that is the activity of interest in this paper. According to Bale, this trialectic of running not only brings into focus different kinds of bodies but also different kinds of
\end{abstract} places and spaces in which these different bodies are reproduced.

2 The special issue of the International Review for the Sociology of Sport on 'sport and space' (1993, Vol. 28, 2/3) is a notable exception.

${ }^{3}$ While acknowledging that many of the training practices would be similar outside the west (Bale and Sang, 1996) the sociocultural, economic and environmental contexts are likely to differ sufficiently to demand that the analysis be geographically delimited.

${ }^{4}$ Similar debates have occurred in other disciplines including environmental sociology (e.g. Hannigan, 2006), political ecology, environmental anthropology, ethnobotany and critical cultural ecology.

${ }^{5}$ Also labelled 'post-natural' or 'post-social' (Castree and Braun, 2006, p.168)

${ }^{6}$ This term is deployed by Ingold to capture the idea that humans are simultaneously organisms within ecosystems (i.e. biological entities) and people within social systems (i.e. social entities).

7 Placing people within / inside environments, rather than 'on' them, is central to Ingold's discussion of the 'topology of environmentalism'. He contests the environmentalist (also evidenced in environmental realism) tendency to talk about the 'global environment' that 'by its very vastness this all embracing environment is profoundly alien to human experience...It is...much too big to be lived in. One cannot relate to its components. The environment we relate to, by contrast, is the one that surrounds us, that constitutes our milieu and our ambience. And this is spherical rather than global in its topology” (Ingold, 2000, p.218). This also illustrates how Ingold's ideas of dwelling are profoundly distinct from environmentalist understandings of 'the environment'.

${ }^{8}$ Ingold acknowledges that his thinking has been influenced by Merleau-Ponty and Bourdieu, writers that we have already identified as particularly important in understanding running bodies. This provides further justification for utilising a dwelling perspective in this context.

${ }^{9}$ We would prefer to see this process as one of co-production and interpret Ingold as seeing it in this way.

10 James Gibson’s (1979) book ‘The ecological approach to visual perception’ is identified by Ingold as critical in helping him to develop his ideas about overcoming the divide between society and nature.

${ }^{11}$ This format has been chosen because a period of training is broken into numerous phases that allow for the strengthening of embodied habit. A period of training may be as long as a year but some athletes might have several periods of training in one year as they may have more than one important competition on which to focus. The ability of the athlete and their coach to reach optimal performance several times in a season is referred to as periodization (Coe, 1996). During a period of training a runner utilises all manner of environments in the process of training themselves (typically in association with advice from a coach) to work towards a peak performance.

${ }^{12}$ In England distance is measured using the imperial system (miles, feet and inches) and this is a convention used by the runners at the heart of the research except for distances covered on the running track where the international athletics rules stipulate metric measurement. Therefore weekly train loads are often referred to as 'mileage'.

${ }^{13}$ Ingold refers to 'wayfinding' as the "life historical process of 'getting around'” (2000, p.232). It is a process that is distinct from map using and "more closely resembles story telling” (2000, p.219), entailing intimate knowledge of an environment that emerges through dwelling and the building of taskscapes.

${ }^{14}$ Sessions may be structured as follows: 5 minutes of effort followed by 90 second break, repeated 5 times; or 2 minutes of effort, followed by one minute break, repeated 10 times or one minute of effort followed by a one minute break twenty times. The rests are kept short enough to allow Richard's body to recover enough to complete the session without over-stressing it. In essence the rest period is directly related to the intensity of the effort.

${ }^{15}$ A hill of approximately 1000 metres in length within the Country Park affords a 30- degree climb. The training phase begins with three repeats and gradually builds towards 6 repeats during the 8 week period enabling the runner to improve their strength. 
${ }^{16}$ This is then followed by 2 times $400 \mathrm{~m}$ at his $1500 \mathrm{~m}$ pace. The reason for doing this is that the exertions on various hills tire the body but do not drain it completely and so the athlete is able to step on the track and perform better than expected over the $400 \mathrm{~m}$ distance. This session is an indication to Richard that the perception of fatigue can be an issue of mind over matter.

${ }^{17}$ This session may be short sprints of $100-300 \mathrm{~m}$ in length with long, almost full recoveries between efforts. 